تمازج لغة الحب ولغة وصف الطبيعة

د.أروى محم أحمد ربيع

تُعدّ حركة الأدب والفكر والحضـارة، في الأندلس، أثراً من آثار البيئة السياسية(1) والطبيعـة في الأنـلس، على الـرّغم مـن أن البيُّة الأساسـية لهـذه الحركـة مشـرقية الأصول والروح.

وهذه الأرض التي أرسى فيها العرب أسس دولة ذات سمات حضـارية جديدة تتميز بطبيعتها الخلابـة، التي تختلف عمّا ألفوه في جزيـرة العرب، ومـا في أرضـها مـن مظاهر الجفاف الذي فرضته الطبيعة عليها.

وإلى جانب البيئة الطبيعية السـاحرة، ببحارها وأنهارها وجبالها ووديانها وأجوائها المعتدلة، كانـت هناك حياة اجتماعيـة(2) متميزة بالانفتاح تتيح لناسها أجواء من الحرية، وحياة الرّخاء، وما ينشأ في ظل ذلك من شيوع الاختلاط واتخاذ ما يُمتّعون به أنفسهم مـن غنـاء وسـماع الموسيقىى، ووسـائل المتعـة والتسلية، ولا شـكَّ أن كلَّ هذه المظاهر إنمـا تمت في ظلّ مدن مزدهرة بعمرانها وقصسورها، ومتتزهاتها، ومجالس اللهو فيها. في ظِلِّ هذه الأجواء الطبيعية الجميلة، ومظاهر الحياة الاجتماعية المنفتحة وما يسودها من حرية ظهر الأدب العربيُّ في حُلّة جديدة في لغته وصوره ومضـامينه وشكله وما أتاحه ذلك من ولادة فنين جديدين يتمثلان بالموشح والزجل. (1) ابن زيدون، الديوان، تحقيق حنّا الفاخوري، دار الجيل، بيروت،الطبعة الأولى 1990، ص 5-7.

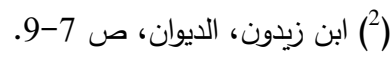


ومن ثمّ فمن المتوقع أن نجد ابن زيدون، الذي سينصَبُّ هذا البحث على دراسـة جانب جديد من لغته، يقول، في وصف أحد متنزهات المعتضد(3):

للِهَهـوَى عَـنْ مَحَلِّهـــا تعــويضُ للِمُنْـى مــن سَــحَابِها تَـرويضُ

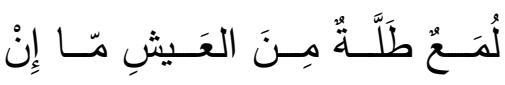

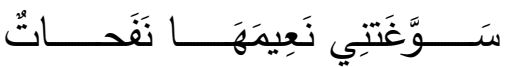

من خلال التّمعن في هذين البيتين، تأسرنا جماليّة اللغة والأسلوب ، من خلال توظيف الثّاعر لمفردات تعبر عن حالته النغيّة ، إذ جاءت الطبيعة بمثابة مسوغ مهم للحياة ، بتوظيفه (سوّتتي نعيمها نفحاتُ ) ، فكأن الطبيعة تروض ابن زيدون من خلال توظيفه للمصدر (تفعيل) إذ جاءت كلمتي ( تعويض وترويض ) مـع التركيز على حرفي التاء والضـاد بصـتهما مـن الحروف المهموسـة التي تتــاغم مـع الجو العـام للقصيدة ، الذي يتشـح بحزن الثّاعر وكآبتهـ ـ فالتاء والضـاد حرفان مـن مجموعـة الوقفات الأسنانيّة - اللثيّة ـ (1) إذ توحي هذه الحروف بمدى الأزمـة النفسيّة التي تتتاب الثاعر ، فجاءت الطبيعة الأندلسية بمالها مخفقة عليه هذا الضغط . ابن زيدون، أحد الشعراء الكبار في الأندلس، الذين كان للطبيعة الجديدة أثر واضـح في شعره من حيث المعاني ، والصور، وبناء القصيدة. غير أنّ أهمّ ما بدا لي وأنا أدرس شعره لغته التي كان أثر الطبيعة فيها واضحاً جداً إلى حد أنّ شطراً كبيراً منها شكّل

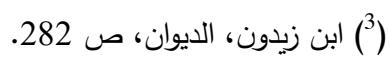




\section{تمازج لغة الحب ولغة وصف الطبيعة}

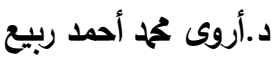

ظاهرة جديدة اشترك في تكوينها الحبّ والطبيعة. وهذه الظاهرة مدار البحث مستمدة من وصف الثاعر ابن زيدون(*) ب: (شاعر الحب

والطبيعة)(2)، فإنعام النظر في شعر ابن زيدون يكثف بوضوح اختلاط لغة الحب بلغة وصف الطبيعة إلى حدّ التمازج والتماهي. ولعلّ هذا ما يشكل ظاهرة جديدة في شعره تستحق الدراسة والبحث. عـرف عـن ابـن زيـدون ولعـه الشـديد بوصـف الطبيعـة، كمـا اشـتهر بحبـه لـولاّدة بنـت المستكفي(*) وهيامه بها. في البدء كان يستعين بمظاهر الطبيعة ،ولا سيما النباتية

فوزي حسن الثايب : محاضرات في اللسانيات ، منشورات وزارة الثقافة ، عمّان طبعة الاولى، 1999، ص165-169. انظر : الخليل بن احمد الفراهيدي : مقدمة كتاب العين : تحقيق عبد الحميد هنداوي ، دار الكتب العلمية ، بيروت ، 2003 2003

تعريف بالثاعر ابن زيدون: هو أحمد بن عبد الله بن أحمد بن غالب المخزومي، ولد بالرّصافة من ضواحي قرطبة من

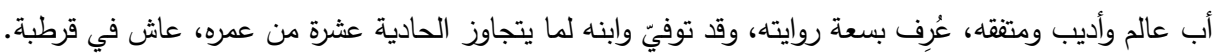

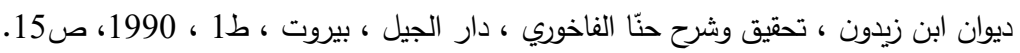

(2) علي عبد العظيم : ابن زيدون ، عصره وحياته وأدبه ، ص 372.

(**) ولادة بنت المستكفي: ابنة الخليفة الأموي المستكفي، الذي تولى الخلافة سنة 1023م/ 414هـ، وخُلع بعد فترة قصيرة

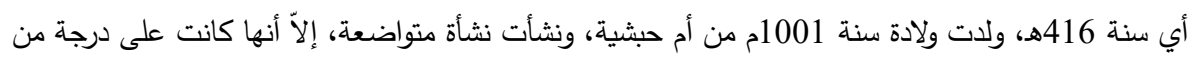

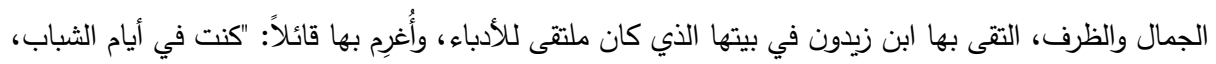

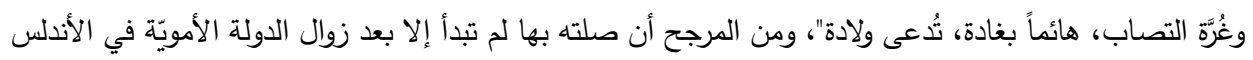

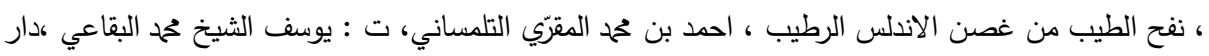

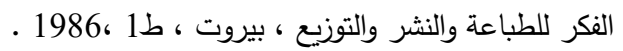


تمازج لغة الحب ولغة وصف الطبيعة

د.أروى محمد أحمد ربيع

في غزله وصفاً لولّادة ، وتشبيهاً لمفاتنها بمفاتن الطبيعة. يا روضـةً طالما أجنَتْ لواحِظَنَا وَرداً ، جَلاهُ الصِّبا غَضَّنا ، ونسرِينَا

مُنَّى ضُرُوباً ، ولذَّاتٍ أفانينا (1) ويا حياةً تملَّيًَا بِزهرتها

تطور هذا المنحى بعد سـنه للقطيعة بين الحبيبين ، الذي اضطر معـه الشـاعر إلى التّوجه إلى الطّبيعة يشكو إليها آلام الفراق، ويطلب إلى برقها أن يوصل السُّقيا إليها

مـن كـان صِـرف الهـوى والـودِّ يا ساري البرق غادِ القصر واسقِ يسقينا

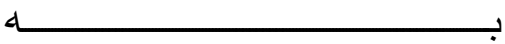

يوجه الثّاعر خطابه للبرق ويستجديه علّه يسقي ولّادة ، وهي تسقيه ، فولّادة هي البرق ، وهي حياته فكل جماليات الطّبيعة تتمثل بولّادة .

(1) (1) (ابن زيدون ، الدّيوان ، ص 390 .

(2) ابن زيدون ، الديوان ، ص 389 ـ

(3) (3) (3ين زيدون ، الديوان ، ص 389. 
وحين يخاطب الحبيبة مباشرة يستذكر الأشجار والغصون والأزهار ، التي كانت تجري في أفيائها اللقاءات السعيدة، وحين طال سجن الثـاعر زاد لجويُهُ للطبيعة يبثها أحزانها ومواجده6

من لَوْ عَلى القُربِ حَيَّا كان يُحيِين (3) وبـا نَسِيمَ الصِّبَا ، بَلِّغ تحِيَّتَنا وحين كثُر خطابه للطبيعة بدأت مرحلة جديدة، إذ كان يجد فيها من يستعين بـه على

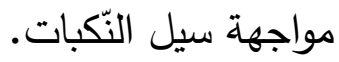
ولا شـكّ في أن لغتي وصف الطبيعـة والغزل، حين تسـتثران معـاً على مدى طويـل، لمعالجـة تجربـة ذاتيـة فـي إطـار قصـيدة واحـدة سـتأتلفان وتتقاربـان، وأنهـــا حين تستخدمان معاً لرسم صورة شعرية بعينها سيتاح لهما مزيد من الألفة والثروع بمحاولة التمازج. أمّا حين يتوجه الثـاعر بالخطاب إلى إحدى مفردات الطبيعـة كالثـجرة أو القـر أو البـرق، ليبثها شـكواه أو يشـرح لهـا أحزانـه فهو يـرى حينئذٍ فيها مخايـل الحبيبـة دون وعسي منـه، ويضطر إلى أن يستعير من خطاب الحبيبة ما يتوجها به إلى الطبيعة، وعلى مدى الزمن، وخاصة حين تغيب الحبيبة نتيجة الهجر أو الفراق بسبب السجن، تبدأ الطبيعة بتعويضــه عـن حضـور الحبيبـة، وتبـدأ اللغـة أيضـاً بمطاوعـة الثـاعر على توجيـه الخطاب إلى الحبيبـة البديلـة. وهكذا يتهيأ الجو لتمـازج لغتين أو استعانة إحداهما بالأخرى، لِتَكون من ثَمَّ لغة ذات سمات جديدة. 
إن للطبيعة أثراً واضحاً في شعر ابن زيدون، فصورها منثورة في تضاعيف قصائده بحيث تشكل ركناً مهماً من بنيتها، إذ تتغلغل في ثنايا صوره وتشكيلاته الشعرية، وفي غزله ومديحه، ونجواه وشكواه، واعتذاره، فهي أداةُ تعبيره، وتصويره البياني، وفي كل فنون

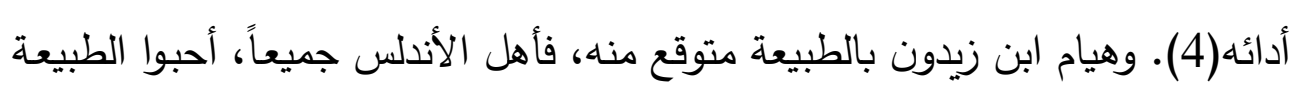
الساحرة الخلابة، وهاموا بها، واندمجوا فيها ووصفوها، وصدروا في ذلك عن صدق عاطفة، تعبيراً عن شدة ارتباطهم وتعلقهم بها. فكيف لا يحبها ابن زيدون؟ ابن زيدون المرهف الأحاسيس ذو المشاعر الرقيقة، الذي ألف أجواء النعيم، فضـلاً عمّا يتمتع به من قدرة على استثفاف معاني الجمل في تجلياتها البهيجة، لذا تغنى بمظاهر الطبيعة واعتبرها ملهمته، فكانت إحدى بواعث الإبداع في شعره. فالطبيعة بتجلياتها الساحرة تستحوذ على مشاعر الثاعر ، وأفكاره، ومن ثم فهي تخضع لسطوة خيالـه، فتظهر تثكيلاتها صورة معبرة عن رؤاه وأفكاره. إن صور الثـاعر وجمله الثـعرية بعامـة هي نتاج تفاعل خيال الثـاعر مـع إيحاءات الطبيعة، فكلما ازدادت وتيرة هذه الإيحاءات تسامت أخيلة الثاعر ليبدع في تصويرها (5).

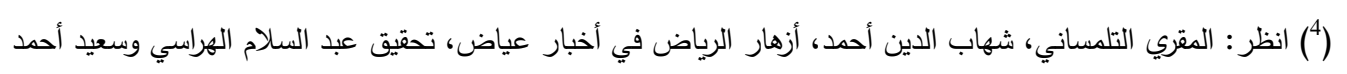

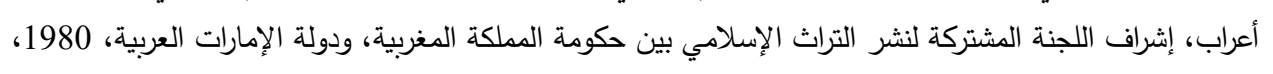

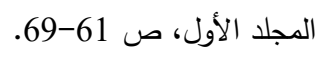

(5) فوزي خضر ، عناصر الإبداع الفني في شعر ابن زيدون، الكويت، 204، ص 168. 
تمازج لغة الحب ولغة وصف الطبيعة

د.أروى محمد أحمد ربيع

ولقد جاءت صور الطبيعة هذه بفعل خيال الثاعر ملأى بالحركة والحياة، فهي في حركة دائبة ترى وتسمع وتثعر وتتحرك وتتعاطف مع الثاعر . وإذا كانت الطبيعة بكل مظاهرها الساحرة والجذابة، مصدر إلهام لابن زيدون، فاستقى من منابعها كلَّ صور إبداعه، فإن أثرها في إبداعه وإلهامـه، قد ازداد إذ شاركته تفاصيل قصـة حبّه وسعادته وأحداث مكابدته مواجد الهجير والقطيعة بينـه وبين ولّادة، وآلام سجنه وما لقيه فيه من مرارة فراق الوالدة والحبيبة والأهل والأصدقاء وعذاب فقدان الحرية . لقد دعت الطبيعـة وِلادة حبّ ابن زيدون لِوَلاّدة ، وشهـدت أعذب لحظات الودّ والصففاء وتساقي كؤوس الهوى، فكانت شريكة الحبيبين في هذه المشاهد البهيجة، في مجالس اللقـاء في أحضـان الرِّّاض، وفي ثنايـا القصـيدة وبين صـورها أيضـاً، فكانـت هـي والحبيبة عناصـر بنـاء كِلّ صـور الإبداع، وتقاسمت هي والحبيبة مهمـة مدّ الثـاعر باللغة التي تُسعفه في تصوير مشاهد السعادة والهناء. وأسـعفت الطبيعـة الثـاعر إبّان معاناتـه ألـم الهجر وعذاب الصـدود، فكانـت معينـة في إيصـال توسـلاته واعتذاراتـه وتمنيـه معـاودة الوصـال، فالطبيعـة كانـت شفيع الثـاعر تتوسل معسه وتستعطف الحبيبة القاسية، وكانت لغـة مفرداتها مطاوعـة للشـاعر في معانيه ورسم مشاهد توسلاته. فالطبيعة نهضت بكل مغرداتها بمهمة ايصال الشكوى

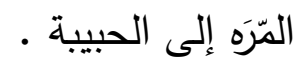


وتجلت براعة الثاعر في المزج بين مفردات الطبيعة بكلِّ ما تشتمل عليه من موجودات، ولغة الحبّ بكل ما فيها من مشاعر الثوق والحنين وتمني اللقاء، وتصوير ألم الفراق، ويتمثل هذا (6):

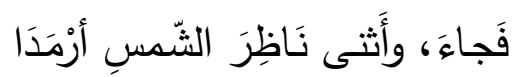

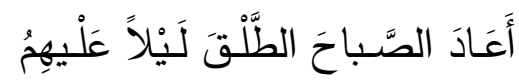

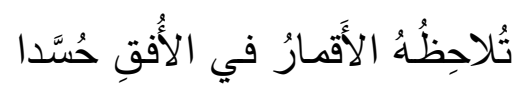

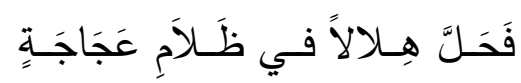

فاستخدام مفردات الطبيعة مثل: الصّباح، والليل، والثّمس، والهلال، والظلام، والأقمار، والأفق، نسجْ منها صوراً فنيّة غايةً في الجمال، فقد أضاف الرَدَ إلى عينِ الثَّمس، وألحق بالأقمار صفة الحسدِ التي يختصُّ بها بعض بني البشر. وفي قصيدة أخرى نجد الثاعر يوظف مفردات الطبيعة لتشاركه آلام الضيق والثدّة التي لازمته في سجنه فراح يستعطف أبا الحزم، ويطلب منه المغفرة بقوله(7):

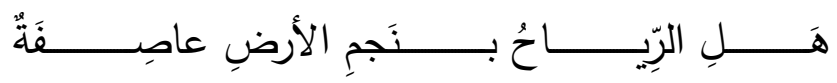

(7) (7) (ابن زيدون، الديوان، ص 37. 
تمازج لغة الحب ولغة وصف الطبيعة

د.أروى محمد أحمد ربيع

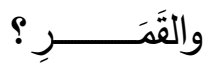

الََّّدَ

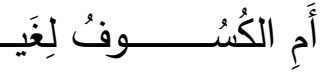

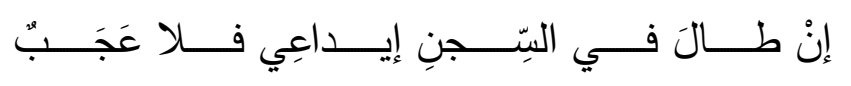

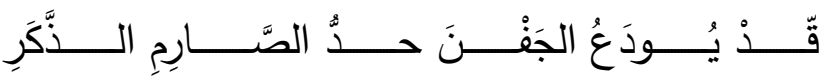

تظهر هنا قدرة ابن زيدون التّصويرية من خلال امتزاج الطبيعة ، وما فيها من مكونات مع أحاسيسه المتأججة، فيتوحد مع الطبيعة، فإذا بها تشاركه معاناته، هذه المشاركة الوجدانية أضافت الحيوية والجمال لهذه الأبيات ، من خلال اللغة التي نهضت بهذه المهمة الجديدة. التي برع فيها ابن زيدون من خلال توظيف الجمل الإنشائية ، التي تجعل من مظاهر الطبيعة عنصراً مشاركاً له في حيرته . فهو يخاطب محبوبته ولّادة (8):

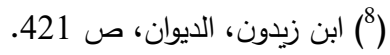


تمازج لغة الحب ولغة وصف الطبيعة

د.أروى محمد أحمد ربيع

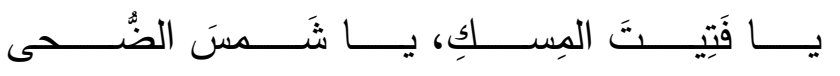

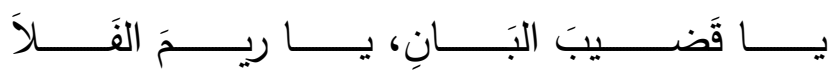

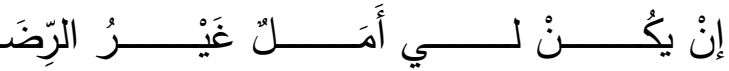

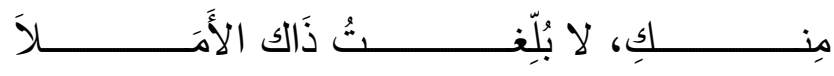

فمحبوبته هي شمس الضُّحى، وقضيب البان، وريم الفلا، ولا أمل لـه في هذه الدُنيا غير

رضاها. فالثّاعر يطوّع الطبيعة ليعبر بها عن مكنوناته تجاه حبيبته ولّادة، وهنا يحارُ

المتأمل: من هي الملهمة الأولى للشاعر ، أهي الطبيعة الأندلسية، أم هي ولّادة؟ 
وغزل ابن زيدون مصدر من مصسادر هذه اللغـة الجديدة، ومحور هذا الحبّ ولّادة بنت المستكفي سـليلةُ بيــت الخلافـة(9)، الغـادة الفاتــة الجمـال الثـاعرة المثقفـة، جليسـة الشعراء والأدباء، المعروفة بدقة الطبع، وكرم النفس، وجمال الروح، وحضور البديهة. استولت هذه الفتاة على مشاعر ابن زيدون فهام بها حباً، وبادلته الحب، فكتب فيها أرقّ القصـائد، حتى اقترن ذكره بذكرها، واسمه باسمها. وتنطوي هذه القصـة على معـان جعلتها موضع اعتبار وعناية فهي تمثل في معناها العام هذه التجربة الإنسانية، بكل مـا جاشت بـ مشاعر الإنسان في أحوال الحب المختلفة(10)، إنّ حب ابن زيدون لولادة كان حباً قوياً عميقاً، فاض بأعذب الشعر ، وباحت قصائده بكثير من الأحوال التي يمرّ بها العاشق من شكوى، وحنين، وعتاب، وهجر • وفي كل هذه الحالات كانت الطبيعة حاضرة وشاهدة على هذا الحب ، فلا عجب أن تشاركه بلغتها وأسلوبها • وما تملكه من سحر فالطبيعة والمرأة تبدوان متلازمتين في شعر ابن زيدون، وبخاصـة في الصور التي تفتنٌّ اللغة في تشكيلاتها، إذ طوّع الثاعر اللغة لهذه المهمة الفنية الصعبة، حين جعل من الطبيعة محوراً تدور حوله قضـاياه تجاه الحبيبة ولادة التي لم تسر علاقته بها على وتيرة واحدة، فبعد عهد الصفاء والمودة، جرت قطيعة، أعقبها تراضٍ، فقطيعة أخرى، 343-337/5 (9) (نظر : نفح الطيب، ( ) سعيد حسن منصور : التجربة الإنسانية في نونية ابن زيدون، الدوحة، قطر، 1983، ص 3. 
فهجر أحزن الشـاعر وأضناه، ولم يعد أمامه للتخفيف من شدة انفعالاته في خضم هذه الأحداث غير الاستعانة بالطبيعة للتعبير عن أساه وعمق حبه لولادة 11، وحزنه لفراقها، وشوقه إلى لقائها، وسعيه لاسترضائها واستعطافها، مستذكراً ما كانا ينعمان به من ود ، وهما في أحضاء الطبيعة ـ فالطبيعة ترعى لقاء اتهما وتسمع تتاجيهما، فامتزج سحر الطبيعة بلوعة الحبّ، وذكريات الهوى، فجاءت أشعاره مزيجاً جميلاً من صور الطبيعة الغناء، والمشاعر المتأججة الدافقة12:

والأفْقُق طَلْقٌُ، ومَرْأَى الأرضِ قد راقَ

كأنَّـــهـ رقَّ لــي فاعتـلَّ إثــفاقَا كمـا شَـَقَتُتَ عـن اللَّبَاتِ أطواقَـا جال النَّدى فيهِ حتَّى مـالَ أعناقَا
إنِّـي ذكرتُــك بــالزَّهراءِ مُشْـــتاقا

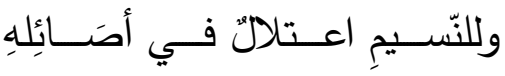

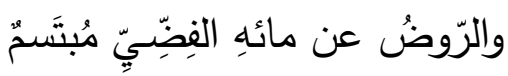
نلهو بما يستميلُ العينَ من زَهرٍ

11 . انظر : علي عبد العظيم : ابن زيدون ، عصره حياته شعره ،ص 360-365 .

12 
ما يمنح هذه الصورة سمة الحيوية ويبثُّ فيها الحركة، أن الثاعر ابن زيدون يتميز بصدق العاطفة، وحرارة المشاعر ، والبعد عن التكلف، ويزيدها في الوقت نفسه إدهاشاً وإثارة للمتلقي، قدرتهـ على ابتكار الصـور الجديدة التي تستمدُّ مادتها من اتحاد الطبيعـة بالحبيبة، وهذا التمـازج هو سرُّ ظهور الطبيعـة بكل مفرداتها، بهذا الشكل الجميل المتتاستق يستمد طراوتـه وجمالـه مـن الحبيبـة في مختلف أحوالها: راضـية غاضـبة معرضــة مبتسـمة. ولهـذا تبـدو الرِّـاض البهيـة، والنسـائم العليلـة، والميـاه المترقرقـة، تشاطره اللوعة على فراق من يحب، ويطرب لله إذ تراه سعيداً مع الحبيبة في مغاني الزهراء أو في صبواته إلى لقاء ولادة عقب فراره من السجن. اللغـة التي وظفت لتصـوير هذه المشاعر المتناقضـة لغـة سهلة منسابة مطوعـة تستجيب للتعبير عن هذه العواطف المضطربة، فيها مزيج من حبّ الطبيعة، ووصف مفاتنها، واستنكار لحظات الهناء في رحابها، والحنين إلى لحظات اللقاء مـع الحبيبة، وهذا يظهر جلياً في قصيدته التي قالها وهو في سجنه، يتذكر قرطبة ومغانيها وقصورها التي أثارت ذكراهـا أثجانه وحنينـه إلى لحظـات اللقاء مـع محبوبته ولادة، غداة عيد

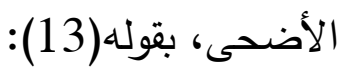

فمـا حَـالُ مَنْْ أَمَسَسى مَشُسوقاً كمـا

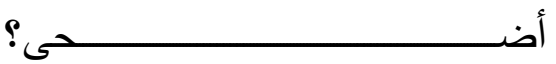

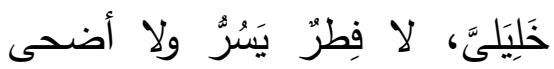

لََيْنْ شَاقِني شَرقُ العُقابِ ، فَلم أَزْن

(ابن زيدون، الديوان، ص 488 (13) (38) 
أخُصُُ بِمَمْحُوضِ الهوى ذِللكَ السَّفحَا

دَواعِيَ ذِكرَى تُعقِبُ الأَسـفَ البَرْحَا

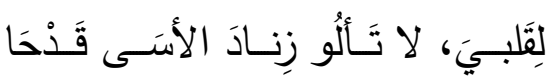

وما انفَكَّ جُوفِيُّ الرَُّصَافَفٍِ مُشْعِرِي ويهتاجُ قَصْرُ الفَارسِيّ صَبابَةً

إلى أن يقول:

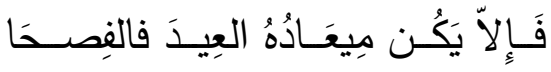

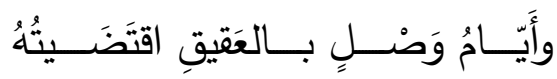

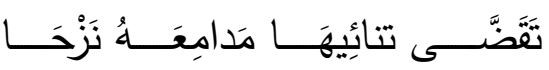
ألا هَــنْ إلــى الزّهـــراءِ أَوْبَــةُ نــازِحِح

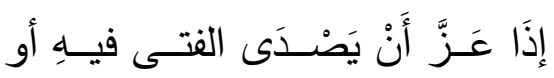

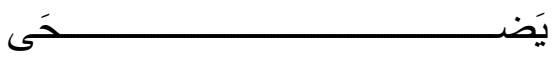

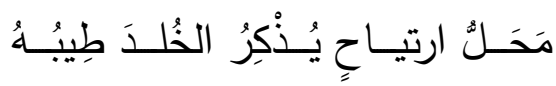
هُنـاكَ الجِمَـامُ الـزَّرقُ تَنْدَى حِفافُهـا

ظِلالِ عِهِدتُ الدَّهرَ فيها فتئَ سمحَا

فهذا الحب العميق، المحمل بصدق العاطفة، والشوق إلى هذه الأمكنة لم يعرف إلاّ في سـياق الحـب والغزل، فالثَّوق، والصّـبابة، والهـوى التي يقداح بهـا زنـاد الأسـى، ثم الوصل، والميعاد، والعتاب، والمدامع. وغيرها من المفردات أليست هي عماد قصيدة 
الغزل؟ بلى إن هذا الخطاب موجه أساساً إلى ديار الثاعر، إلاّ أنه يُظهر مدى شوقه إلى ذكرياته مع الحبيبة في تلك الدّيار كقوله: (وأيامُ وصلٍ بالعقيق اقتضيتُُه). الملاحظ أن ابن زيدون يعدد في غزله إلى وصف الطبيعة، وذكر الأماكن، وهذا ناتج عن تمـازج لغـة الحبب بلغـة الطبيعـة، وهو سـة مـن سـمات هذه الظـاهرة، ومظهر مـن مظاهرهـا لدى ابن زيدون، وهنا يمكن القول إن الطبيعة أثرت الغزل لديـه، ووسعت آفاقه، ومنحته جمالاً، وشعوراً وجدانياً عالياً، وهذا ليس غريباً على ابن زيدون فهو كما

$$
\text { قلنا: (شاعر الحب والطبيعة)(14). }
$$

وجميع قصـائد ابن زيدون تتحو هذا المنحى من المزج بين لغـة الغزل ولغـة الطبيعـة،

$$
\text { كقوله (15): }
$$

ويُظِلِمُ لــي النَّهـارُ وأَنْـَتَ شَمِسـي

فـأجنِي المـوتَ مـن ثـراتِ غَرسِي

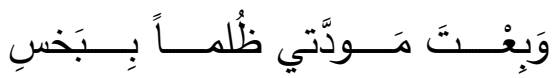

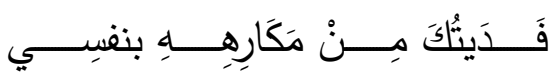

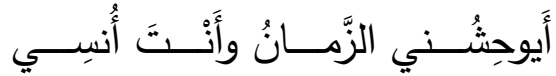

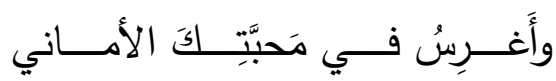

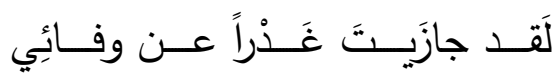

ولـــو أنّ الزّمـــانَ أطــــاعَعُكـــــي

( 14 علي عبد العظيم: ابن زيدون عصره وحياته وأدبه، ص 374.

(ابن زيدون، الديوان، ص 458 (15) ( 
في هذه المقطوعة نجد الشاعر يعاتب حبيبته عتاباً رقيقاً يبدأه بتساؤل عن سبب وحشة الزّمان وإظلام النهار ، بالرّغم من أن الحبيبة هي مصدر الأنس، ومصدر الإضـاءة فهي كالثمس نوراً وبهاءً، ومـع ذلك فهو يغرس مفردات هذه المقطوعـة: (النَّهار، والثَّمس، والثِّمار ، والغرس) كلّها مفردات مستمدة من أحضان الطبيعة نسجها الثَاعر بطريقـة رائعـة تعبـر عن عتابـه ولومـهـ لهذه الحبيبـة، وهنـا لا يمكن فصـل مفردات الطبيعة عن مفردات الغزل، فهما تتبادلان الوظيفة التعبيريـة ، وكأن الطبيعة تتغلغل في ثنايـا قصـائد الغزل(16)، وهذا مـا أكسب شـعر ابـن زيدون هذه الخصوصـية والروعـة، فالتّمـازج والاختلاط بين لغـة الحب ولغـة الطبيعـة، كادا يكونـان، موضـوعاً واحداً، وكأن الطبيعة هي التي تثير في نفسية الثاعر معاني الهوى، وتحرك مشاعره، وتصل بينه وبين محبوبته، وهذا المزج لا يتهيأ إلاّ للغة خاصة يمنحها شاعر عملاق دلالاتها الجديدة التي تؤهلها للنهوض بهذه المهمة، وهذا التطويع البارع للغة، وفّر أداة قادرة على التعبير بصدق وإثارة، عن معاني الشاعر وأخيلته وصوره ورؤاه، وتصوير تفاصيل المعاناة في كل مراحل هذه العلاقة المعقدة مع ولاّدة من لقاء، وهناء، وهجر ،

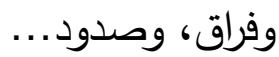

( ${ }^{16}$ انظر : سعد إسماعيل شلبي: البيئة الأندلسية وأثرها في الثعر، عصر ملوك الطوائف، دار نهضة مصر للطبع والنشر ، 1978، ص 180. 
تمازج لغة الحب ولغة وصف الطبيعة

د.أروى محم أحمد ربيع

إنّ من أهم مقومات إبداع ابن زيدون وتجليات عبقربتهِهِ هذه اللغة الجديدة التي تجلَّت من خلال القصائد والمشاهد الثعرية، وشكّلت عنصر التمييز الذي تفوّق به الثاعر عن غيره مـن شـعراء عصـره، إذ يتجلى اختلاط لغـة الحسب بموجـودات الطبيعـة بشكل واضـح، وكـأن وصـف الطبيعـة والغزل بالمحبوبـة هــا مـوردان أساسـيان لهـذا الفـن الجديد، نتج عنهما تمازج في لغتهما وصورهما. ولا ضير من العودة إلى أثر الطبيعة الأندلسية الساحرة التي كانت من أهم المصادر التي استقى منها حسَّه المرهف، ومشاعره الصادقة ما يعبر عن لهفته وشوقه اللذين يمثلان بؤرة غزله كما أكدّ شوقي ضيف بقوله: "إن غزل ابن زيدون واسع التأثير بما فيه من عمق الجوى وعذاب الحب وحرقة العشق"(17). بل إن شوقي ضيف يعدّه أهم شاعر وجداني في الأدب الأندلسي فهو "أول من اعتصر فؤاده شعراً عذباً فيه جوى وحرقة وهـوى ولوعـة"(18)، وهـو قريـب في هـذه الجوانـب مـن مشــاعر العـذريين العميقـة الصادقة، وإن كان ما يميز ابن زيدون عن غيره من الثعراء العذريين أنها كان ينال من محبوبته، فليس كلٌ حبه تعبيراً عن الحرمان بقدر ما هو تعبيرٌ عن الحب العميق

(17)

(المصدر السابق نفسه، ص 42، 43. 
تمازج لغة الحب ولغة وصف الطبيعة

د.أروى محمد أحمد ربيع

والثوق الدائم، بل إن بعض نماذج شعره توحي بالإشباع، كما يظهر في النونية، إذ

يقول(19):

ورداً جَـلاهُ الصِّــبا غَضَّــا ونسـرِينَا

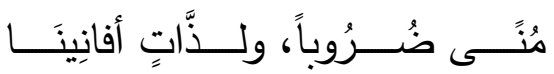

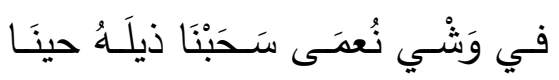

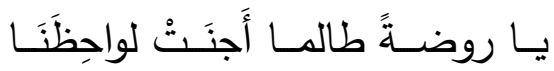

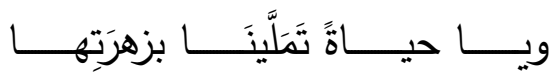

ويـا نعيمـاً خَطرنـا مِـن غَضـــارِتِهِ

فالثاعر يعبر عن مختلف أحواله مع محبوبته ولادة، بما في ذلك من صفاء وتواصل، وما فيه من شقاء وبعاد وشكوى، وألم وفراق، وفي جميع هذه الأحوال يظهر أثر طبيعة الأندلس الساحرة ماثلاً في هذا الغزل، لأن الطبيعة مرتبطة في مخيلته بالحبيبة، فهي تضـكك وتزهو وتتراقص لسعادة الشـاعر بلقاء محبوتـه، وتحزن على حزن الشـاعر لهجر محبوبته، يقول(20):

فمـا حسالُ مسن أمسَسى مَشُـوقاً كمــا

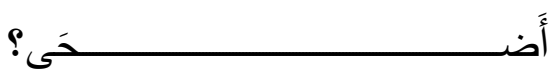

خليــيَّ ،لا فِطــر يَسُرُّ ولا أضــحى

لَئنْ شَاقَنِي شَرقُ العُقَابِ ، فلم أزل

(ابن زيدون، الديوان، ص 390 (19)

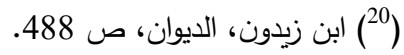


أخصُّ بممحُوضِ الهوى ذلك السَّفحَا

فمشاعر الشاعر تجاه مظاهر الطبيعة مشاعر محب عاشق. ولغة خطابه لغة غزل. إذ يشكل الشـاعر صـوره من مفردات الطبيعـة، وتظهر عواطفـه المتدفقـة فتتشـابك مـع صور عشقه لمحبوبته ولادة، لذا جاءت جمله الشعريـة منسوجة حتى بدت كحُلَّةٍ سُداها الغزل ولُحمَتُها مفاتن الطبيعة، فتلاحمن تلاحماً حقيقياً جعل مظاهر الطبيعة وعلاقته بمحبوبته يتماهى أحدهما بالآخر، لذا فهو حين يربد أن يظهر جمال الحبيبة "يتمثل "يل جمال الطبيعة في الحبيب، فيناديه بغضن البان والقرر"(21): وغُصــنَ البــانِ يرفُهـن فــي وِشَــاح

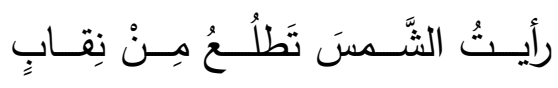

$$
\text { وقوله في قصيدة (يا راحتي وعذابي)(22): }
$$

(ابن زيدون، الديوان، ص 404 (21) (2) (2)

(22) (ابن زيدون، الديوان، ص 410. 


\section{د.أروى محمد أحمد ربيع}
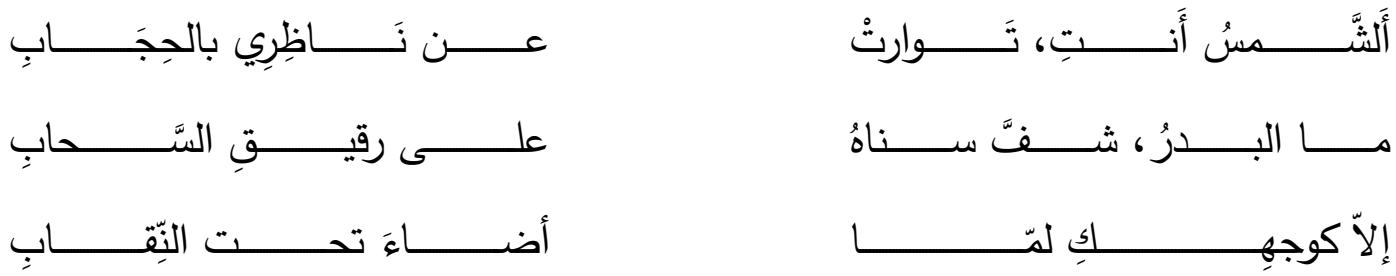

المفردات: (الثّمس، والبدر ، والسّحاب، والإضـاءة) كلّها مستوحاة من الطّبيعة ، وهذا مـا يؤكد ظهور أثر الطبيعـة في شـعر ابـن زيدون، فهو ماثلُ في معظم قصـائده ، "فالطبيعة لديه تمنح شعر الحب والغزل نغماً جميلاً تتجاوب أصداءه، طبيعة فاتـة تسبغ على المحبوب كل صفات الجمال"(23). فالتّمـازج بين لغـة الحب ووصف الطبيعـة انطلقت مـن الحب أولاً، لأن عاطفـة الثـاعر القويـة المحملة بالافتتان بجمال الحبيبة جعلته يلجأ إلى معطيات الطبيعة ليعبر من خلالها عن هذا الجمال تشبيهاً ومقارنة ومفاضلة، أي أن الثاعر يستعير من مفردات الطبيعـة مـا يصف بـه جمال المرأة، وبهذا تكـون الطبيعـة دخلت في بنـاء القصيدة الغزلية، وأوجدت سمة التمازج بين وصف الطبيعة ومفرداتها ومظاهرها، وبين علاقة الثاعر بمحبوبته في جميع أحوالها من رضـا ووصـال وعشق وغضب وهجر وفراق، (23) جودة الرّكابي: الطبيعة في شعر الأندلس، مكتبة أطلس، دم، 1970، ص 38. 
وهذا ما بيّنه الرّكابي بقوله: "إنّ الحبّ عنده أساس لتعلقه بالطبيعة، ومحاسن المحبوبة تجد نظائرها في الطبيعة، بل إن الحبيب لأجمل منها. إنّها أجمل من البدر وأبهى، ولـو أنسّه بـات عنـده مــا تطلـع إلـى بـدر السـماء"(24)، وهـذا واضــح فـي قـول

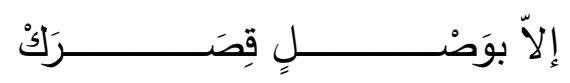

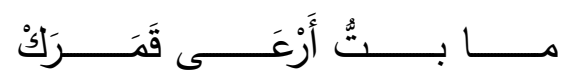
الشاعر (25): (25) (25)

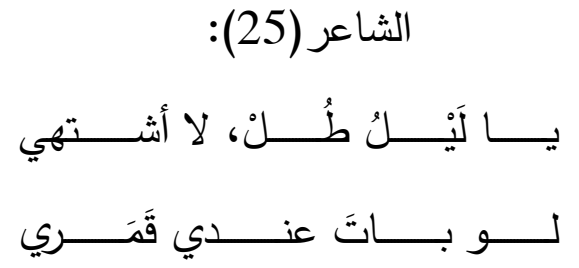

فاللغة في هذين البيتين سلسلة سهلة مناسبة، تجمع بين أحوال الطبيعـة والحب، فلفظة القمر الأولى في صدر البيت الثاني تشير إلى الحبيبة، وفي عجزه تشير إلى القدر الحقيقي الموجود في وسط السماء، وهذا تمّازج لا بل تماهٍ واضح بين مفردات الطبيعة ولغة الحب، وظّّفه الثـاعر بمهارٍ عالية. ونلاحظ أن الثـاعر كعادة الشعراء العرب ربط في البيت الأول بين الليل ولقاء المحبوبة، ففي حالة اللقاء يتمنى أن يطول الليل، وفي حالة البعد يتمنى أن يقصر ، وهنا يقصد الشاعر أنه بحضور الحبيب لا داعي لوجود القمر، فصورة الحبيب وحضوره يُغنيان عن حضور القدر وإضـاءته، وهذه قمَّة

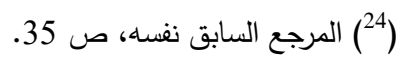
(ابن زيدون، الديوان، ص 436 (25) (25) 
التمـاهي بين المحبوبـة ومفردات الطبيعـة، وهذا يدل على مدى التمـازج بين الحب والطبيعة.

وحيثـا أجال المتلقي نظره في معاني الشـعر عند ابن زيدون، يجد نفسـه أمسام مشـاعر الشوق والحب التي ارتبطت بشكل لافت مع مفردات الطبيعة ومعطياتها، إلى حدّ أن الثاعر وحبيبته ولّادة أصبحا يشكلان سرّين متماهيين، مع أحد مظاهر الطبيعة، وهو الظلماء، وهذا ما يظهر جليّا بالأبيات الآتية (26):

والسَّعدُ قد غَضَّ من أجفانِ واشينا

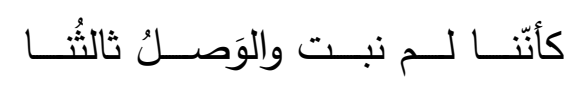
ففي مواقفِ الحشـر نلقـاكم ويكفينـا إن كان قد عَزَّ في الدُّنيا اللَّقاءُ بكم

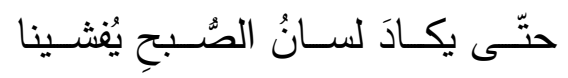

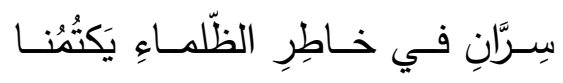

لقد نهض بمهمة اخفاء الثاعر وحبييته خاطر الظلماء، وهذه مهمة لا يقوم بها إلاّ إنسان. وقد أضفى الثاعر على خاطر الظلماء سمات إنسانية، فصار الليل إنساناً ثالثاً، وهذا تماهٍ جديد بين الحبيبين والطبيعة. أمّا الصباح فقد منحه الثاعر صفة الإنسان فجعل له لساناً لكي يفشي السّر بقدومه، وهذا تماهٍ مضاف. ولا يتأتى للشاعر صنع مثل هذه (ابن زيدون، الديوان، ص 391 (26) 
الأنسنة إلا من خلال لغـة مُدّربة على هذه المهمة. وفضـلاً عن براعة هذه اللغة في صناعة هذه التشكيلات التشخيصية، فإن ما لدى ابن زيدون من براعة في النسيج، وإتقان السّبك يسهم في تمكين اللغـة الجديدة من أداء مهمـة التمازج والتآلف، وإنتاج جمل شعرية، وصسور يصسب على المتلقي التمييز الدقيق بين مـا هو من رصسيد الغزل، وما هو من رصيد معجم الطبيعة. يضـاف إلى كل هذا الإبداع أن ابن زيدون استطاع أن يستوحي أجمل ما في الطبيعة، وأجمل مـا في المرأة من مظاهر جمالية رائعـة ليمزج بينها، ويُشكل صـوره الشعرية السـاحرة، من خلال ألفاظ المعجمين الوصفي والغزلي المستمدين من عالم الطبيعة، وعالم المرأة.

هذا واضح في هذه الصورة الشعرية التي تجمع بين مفاتن الحبيبة ومفاتن الطبيعة(27):

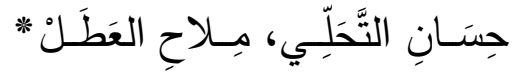

بيــانِع رَوْضِ المِّـــبا المُقَتَبــلـ

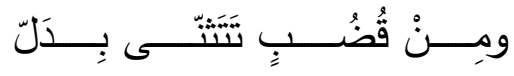

بَدَت فـي لِـدَاتِ كَزْهــرِ النُّجــومِ

مَثَـــينَ يُهـــادِينَ رَوضَ الرُّبَـــى

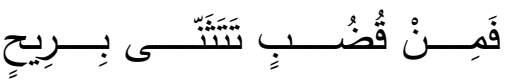

(ابن زيدون، الديوان، ص 199.

(") اللدات: من هُن بعمرها/ العَطلُ ضدَ التخّلي، وهو الخلّو من الحلى. 


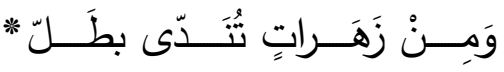

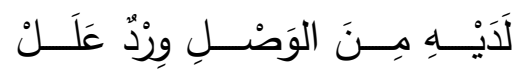

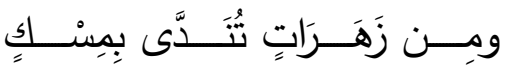

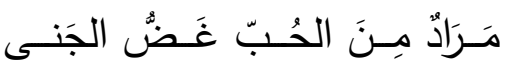

هذه صورة متثـابكة المفردات من عالمي الطبيعة المحملة بصفات الحبيبة وصديقاتها، فهن في مقتبل الصِّبا يمشين بدلال، كالرّوض المليء بالأزهار المتفتحة، وهنّ يشبهن النّجـوم الزّاهـرة، إذ يتمـايلن بـدلالٍ بـين أحضـان الطبيعـة، والمـاء هـو الذي يـرويهنّ بالحياة، فهي صورةٌ مفعمة بالأمل، والحياة، والتفاؤل، وفيها استطاع الثـاعر أن يمزج بين جمال الحبيبة، وجمال الطبيعة، بلغة بارعة الدقة.

وليس من المبالغة القول بأن المصدر الحقيقي للجمال في هذا المشهد الشعري هو اللغة المصـوغة ببراعـة، فضــلاً عمـا في ألفاظهـا مـن سلاسـة مــع حسـن اختيـار الثــــر لمفرداتها، لترسم هذا التمازج بهذه الطريقة الفنية البارعة. ومن مظاهر البراعة في هذه اللغة، أن بعض مفرداتها تتنمي إلى حقلين لغويين مختلفين، فصارت صالحة للتّوظيف في الغزل، وفي وصف الطبيعة مثل: (روض، وقضيب، 
وزهرات) مُظهراً من خلالها مفاتن الحبيبة وواصفاً لجمال الطبيعة، محاولاً استخلاص أبرز المظاهر الجمالية في كليهما. وهكذا تداخلت مفردات الطبيعة مع مفردات الغزل، ومن ثم تداخلت أيضاً صور الحبيبة مع صور الطبيعة، وهذا ظاهر في قوله(28):

فـازداد منــه الضُّـحى فِي العَيْنِ

اقاق إشـ

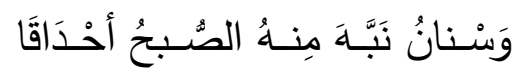

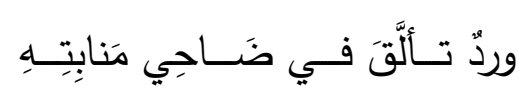

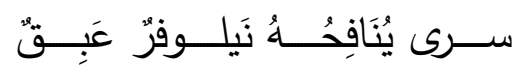

فالثاعر يستعير لورد النيلوفر أحداقاً ويجعله وسنان، ويظهر النُّعاس في عينيه، غير أن الصبح ينبهه فيفيق من نعاسه، وهنا يظهر أن ابن زيدون عندما يرسم صور الطبيعة،

$$
\text { يستعير لها من مفردات دنيا الحبيبة. }
$$

وهذه الخصـائص تؤكد مدى تمكن ابـن زيدون من التعبير عن صـوره، ومعانيـه بيسر ووضوح من خـلال مزج لغـة الحب بلغـة الطبيعة، فيتداخل موضـوعا الغزل ووصف الطبيعة حتى ظهرا كأنَّهما موضوع واحد. أخلص من هذا البحث بالنتائج الآتية :

(ابن زيدون، الديوان، ص 399. 
1. إنّ طبيعة الأندلس الخلابة أثرت بشكل جلي وواضح في شعر ابن زيدون ، من حيث الألفاظ ، والصور ، والدّلالات ، بل تعدّت ذلك لتشكل ظاهرة جديدة هي اشتراك ألفاظ الطبيعة بلغة الغزل لدرجة التّمازج والتّماهي. 2. وظّف ابن زيدون الطّبيعة ليعبّر من خلالها عن حبّه الثّديد لولّادة بنت المستكفي ، فالطبيعة بكل جمالياتها هي ولّادة . 3. نتج عن تمازج لغة الحبّ ولغة وصف الطّبيعة ، لغة جديدة ذات سمات خاصة معبرة عن رؤى الثاعر وأفكاره ، من خلال تثكيلات جديدة للصورة ، مفعمة

$$
\text { بالحركة والحياة. }
$$

4. وعليه فإنّ وصف الطبيعة والغزل هما موردان أساسيان لهذا الفن الجديد. وأخيراً:

هذا البحث يفتح ميداناً واسعاً وجديداً للباحثيين للخوض في بحر لغة ابن زيدون، وصوره لاكتثاف جماليات جديدة للغة الحب ، ووصف الطبيعة. 
1. ابن زيدون، ديوانه، تحقيق حنّا الفاخوري، دار الجيل، بيروت، ط1، 1990. 2. جودة الرّكابي، في الأدب الأندلسي، دار المعارف، القاهرة، 1960. 3. الخليل بن احمد الفراهيدي : العين : تحقيق عبد الحميد هنداوي ، دار الكتب العلمية

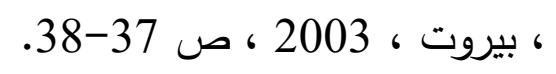

4. سعد اسماعيل الثّلبي، البيئة الأندلسية وأثرها في الثعر، دار النهضة للطبع والنشر، لِّرو،

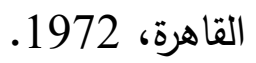

5. سعد حسين منصور ، التجربة الإنسانية في نونية ابن زيدون، الدوحة، قطر ، 1983. 6. شوقي ضيف، ابن زيدون، دار المعارف، مصر، ط9، 1979. 7. علي عبد العظيم، ابن زيدون، عصره وحياته وأدبه، مطبعة الرسالة، القاهرة، 1955. 8. فـوزي حسن الثـايب : محاضـرات في اللسـانيات ، منشـورات وزارة الثقافـة ، عمّـان طبعة الاولى، 1999، صوني هن 165-169. 9. فوزي خضر، عناصر الإبداع الفني في شعر ابن زيدون ، الناشر مؤسسة جائزة عبد العزيز سعود البابطين للإبداع الشعري ، تونس، 2004. 10. المقرّي التلمسـي، أحمد بـن حمد، أزهـار الريـاض في أخبار عيـاض، تحقيق عبد السـلام الهراس وسعيد أحمد أعراب، إشراف اللجنة المشتركة لنشر التراث الإسـلامي بين حكومة المملكة المغربية وحكومة دولة الإمارات العربية، 1982. المقرّي التلمساني، أحمد بن حمح، نفح الطيب من غصن الأندلس الرّطيب، تحقيق محيي الدين عبد الحميد ،ط1 ، مطبعة السعادة ، مصر 1949. 